\title{
Multiplex-PCR serotyping of Listeria monocytogenes isolated from human clinical specimens
}

\author{
Rafaela Moledo de Vasconcelos ${ }^{2}{ }^{+}$, Antonio Eugenio Castro Cardoso de Almeida ${ }^{1}$, Ernesto Hofer, \\ Nicéa Magaly Matias da Silva ${ }^{3}$, Victor Augustus Marin¹/2
}

Laboratório de Zoonoses Bacterianas ${ }^{1}$ Departamento de Microbiologia ${ }^{2}$ Programa de Pós-Graduação em Vigilância Sanitária, Instituto Nacional de Controle e Qualidade em Saúde-FIOCRUZ, Av. Brasil 4365, 21040-900 Rio de Janeiro, RJ, Brasil ${ }^{3}$ Clínica Perinatal de Laranjeiras, Rio de Janeiro, RJ, Brasil

The genus Listeria is composed of six species of which Listeria monocytogenes is considered the single pathogenic species that causes listeriosis in humans. Of the 13 serovars of $\mathrm{L}$. monocytogenes, $1 / 2 a, 1 / 2 b$ and $4 b$ are responsible for the majority of clinical cases. The aim of this work was to detect $\mathrm{L}$. monocytogenes in the cerebrospinal fluid sample of premature newborns and to characterize this sample using biotyping, serotyping and molecular typing. The results indicated the presence of $\mathrm{L}$. monocytogenes in the clinical sample studied. Moreover, the isolate was identified as the $4 b$ serovar that was characterized by the presence of a unique 691 bp band after analysis using the Multiplex-PCR technique. The results of repeated Multiplex-PCR and sequencing have indicated that the L. monocytogenes isolate was an atypical $4 b$ serovar, which is the first time this finding has been reported.

Key words: Listeria monocytogenes - listeriosis - Multiplex-PCR - cerebrospinal fluid

The genus Listeria is composed of six species including Listeria monocytogenes, Listeria innocua, Listeria ivanovii, Listeria seeligeri, Listeria welshimeri and Listeria grayi. Only two of these species, namely L. monocytogenes in humans and L. ivanovii in other mammals, are considered pathogenic (Gasanov et al. 2005).

L. monocytogenes can survive and grow under various ambient conditions and is known as the pathogen that causes listeriosis. L. monocytogenes is a gram-positive bacterium that is mobile, non-spore-forming, and is characterized by a rod-shaped morphology. L. monocytogenes belongs to the facultative intracellular bacteria that invade, replicate and multiply in a variety of cells. Neonates, pregnant women, the elderly and the immunocompromised populations are particularly at risk of infection. The disease can result in an abortion, in addition to stillbirths, septicemia, meningitis, encephalitis and possibly death. The presence of this bacterium in the processing of foods and its natural distribution within the environment coupled with its inherent resistance and ability to grow in some foods, makes it difficult to control and regulate (Bubert et al. 1999, Nelson et al. 2004, Hofer \& Hofer 2005, Gandhi \& Chikindas 2007).

L. monocytogenes can be found in a wide variety of raw and processed foods. Dairy products such as soft cheeses have been associated with Listeria contamination and have been implicated in severe outbreaks (Hofer et al. 2006).

+ Corresponding author: rafamoledo@gmail.com

Received 1 November 2007

Accepted 26 November 2008
L. monocytogenes strains are serotyped according to their somatic and flagellar antigens. Although 13 serovars have been described, only three of these serovars, specifically $1 / 2 a, 1 / 2 b$ and $4 b$, account for the majority of clinical cases. Doumith et al. (2004a) affirms that at least $95 \%$ of strains isolated from contaminated foods and infected patients were of serotypes $1 / 2 \mathrm{a}, 1 / 2 \mathrm{~b}, 1 / 2 \mathrm{c}$ and $4 \mathrm{~b}$. Interestingly, while serovar $1 / 2 \mathrm{a}$ is the most frequently isolated strain from contaminated foods, the majority of epidemic listerioses were caused by the type $4 \mathrm{~b}$ strain.

Multiplex-PCR is a variant of traditional PCR techniques that introduces two or more sets of primer pairs with specificity for different genes or gene regions. For L. monocytogenes serotyping, a PCR-based method was developed to probe four gene targets. The four major serotypes $1 / 2 \mathrm{a}, 1 / 2 \mathrm{~b}, 1 / 2 \mathrm{c}$ and $4 \mathrm{~b}$ can produce four distinct PCR profiles with properly designed primer pairs. This technique can be easily adapted to different laboratories, is quick and reproducible (Doumith et al. 2005). The Multiplex-PCR analysis is utilized to detect the presence of virulence-associated genes of $L$. monocytogenes (Kaur et al. 2007). It was developed for rapid speciation and virulence determination of L. monocytogenes (Liu et al. 2007).

The aim of this work was to identify the species of Listeria that is present in a particular clinical sample and to determine the serovar through biotyping, serotyping and molecular typing using the Multiplex-PCR method, as described by Doumith et al. (2004a).

\section{SUBJECTS, MATERIALS AND METHODS}

The clinical strain was isolated from a sample of the cerebrospinal fluid (CSF) from a newborn whose birth occurred at the 7th month of gestation. The newborn's mother reported a fever and inertia after consuming gorgonzola cheese. The strain that was isolated from the CSF sample was cultured for $16 \mathrm{~h}$ in nutrient-rich broth and the enriched culture was spread onto a chromogenic 
agar plate (Oxoid) that is specific for L. monocytogenes (Scotter et al. 2001). Five presumptive colonies were selected and biochemical identification of L. monocytogenes was performed in accordance with methods described by Scotter et al. (2001). The isolated colonies were serotyped on the basis of somatic $(\mathrm{O})$ and flagellar $(\mathrm{H})$ antigens, according to Seeliger and Höhne (1979) in the Bacterial Zoonosis Lab. of Oswaldo Cruz Institute/Fiocruz. The Multiplex-PCRs were performed using four primer pairs that were specific for L. monocytogenes in addition to one primer pair that was specific for Listeria spp. (Doumith et al. 2004a). The amplified fragments were electrophoresed in a $\%$ agarose gel (in TBE buffer), stained with ethidium bromide solution $(10 \mathrm{mg} / \mathrm{mL})$, visualized with a UV transluminador and photographed.

\section{RESULTS}

In the chromogenic agar, formation of blue halo colonies characteristic of $L$. monocytogenes was observed. The isolated colonies were positive for glucose, maltose and rhamnose, negative for manitol and xilose. They were catalase-positive, small gram positive bacteria that were rod-shaped, and capable of producing a narrow beta-hemolysis zone on sheep blood agar. In addition, results from a CAMP test using beta hemolysin-producing Staphylococcus aureus were positive and a tumbling motility test at $30^{\circ} \mathrm{C}$ indicated that the bacteria were motile. The conclusive identification of L. monocytogenes serovar $4 \mathrm{~b}$, genus $23 \mathrm{~S}$, hly + , was performed according to the guidelines reported by Rocourt et al. (1983). Analysis of the Multiplex-PCR data in accordance with Doumith et al. (2004a) indicated a variety of bands, including a 370 bp band (Listeria spp.), a 471 bp band ( $L$. monocytogenes serovar 1/2b, 3b, 4b, 4d, 4e), a 597 bp band (L. monocytogenes serovar $4 \mathrm{~b}, 4 \mathrm{~d}, 4 \mathrm{e})$ and a 691

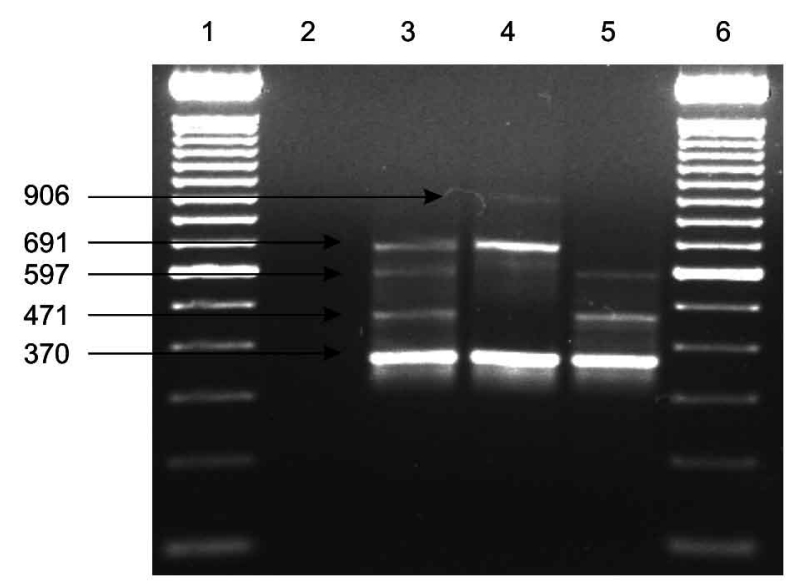

Representative Multiplex-PCR amplification patterns of clinical isolate of Listeria monocytogenes analyzed by $2 \%$ agarose gel electrophoresis. Lanes 1, 6: molecular weight marker (100 bp, Invitrogen); 2: Multiplex-PCR negative control; 3: L. monocytogenes isolated (370, 471, 597, $691 \mathrm{bp}$ ); 4: positive control 1, ATCC 7644 (INCQS 00266) (370, 691, 906 bp; Serovars: 1/2c and 3c); 5: positive control 2, ATCC 19117 (INCQS 00327) (370, 471, 597 bp; Serovars: 4b, 4d and 4e). bp band (L. monocytogenes serovar $1 / 2 \mathrm{a}, 1 / 2 \mathrm{c}, 3 \mathrm{a}, 3 \mathrm{c}$ ) (Figure). The strains were identified as belonging to the L. monocytogenes serovar $4 \mathrm{~b}$. The reproducibility of the 691 bp fragment was ratified by a repeated MultiplexPCR assay and a Simplex-PCR. Direct sequencing of this band proved that this fragment is the gene lmo0737 (NCBI Access: EU980451).

The results of biotyping, serotyping and molecular typing confirmed the presence of L. monocytogenes. However, the appearance of the $691 \mathrm{bp}$ fragment in the Multiplex-PCR analysis was not characteristic of the $4 \mathrm{~b}$ serovar. Studies from Doumith et al. (2004b) report a relationship between the two larger genomic divisions of species that are represented for serovars strains $1 / 2 \mathrm{a}$ and $4 \mathrm{~b}$, suggesting a possible horizontal gene transfer event. This result suggests that the strain identified in this work appears to be a unique $4 \mathrm{~b}$ serovar that has undergone a gene transfer event. In accordance with the work of Chen and Knabel (2007), the lineage I, containing serovars $1 / 2 b, 3 b, 3 c$ and $4 b$ of the L. monocytogenes and its isolates, include major epidemic clones of $L$. monocytogenes that cause a large number of human listeriosis cases. Previous molecular subtyping studies have identified four major epidemic clones of L. monocytogenes, where three of these major epidemic clones (ECI, ECII and ECIV) belong to serovar 4b. Among the 13 serovars of L. monocytogenes, isolates from serovars $1 / 2 \mathrm{a}$ and $4 \mathrm{~b}$ account for most of the major listeriosis outbreaks and, interestingly, all identified epidemic clones of $L$. monocytogenes belong to these two serotypes. The serovars $1 / 2 \mathrm{a}$ and $4 \mathrm{~b}$ are characterized by the specific markers $1 m o 0737$ and ORF2110, respectively. Studies from Doumith et al. (2004a) shows that the marker $1 m o 0737$ produces a $691 \mathrm{bp}$ fragment in 1/2a isolates.

\section{DISCUSSION}

In agreement with a report by Ericsson et al. (1995), the majority of the cases of human listeriosis over the past decade have been caused by the L. monocytogenes serovar 4b strain. Results from Kathariou (2002) also affirms that the serovar $4 \mathrm{~b}$ has been responsible for numerous sporadic cases. Furthermore, Gray et al. (2004) reported that the majority of cases of human listeriosis outbreaks have been caused by serovar $4 \mathrm{~b}$. However, only in rare occasions does a non- $4 \mathrm{~b}$ serovar strain of listeriosis account for numerous outbreaks. Jacquet et al. (2004) reports that most of the major food borne outbreaks due to invasive listeriosis in both Europe and North America have been caused by L. monocytogenes strains belonging to serovar 4b. Doumith et al. (2004b) reported that the majority of sporadic cases of foodborne outbreaks have been caused by serovar $4 \mathrm{~b}$ strains, suggesting that these strains may possess unique virulence properties. Upon relating the serovar distribution with its geographic origins, Hofer et al. (2006) observed a predominance of the $4 \mathrm{~b}$ serovar occurring in all regions of Brazil during the periods of 1969 and 1972-2000. Ramaswamy et al. (2007) reports that the most invasive outbreaks were caused by $4 \mathrm{~b}$ serovar.

The isolate described in this study demonstrated that a new bacterial strain can emerge with variations that result 
from horizontal gene transfer. This is an interesting and significant result considering that the serovar $1 / 2 \mathrm{a}$ is the most frequently isolated food borne pathogen, although the majority of epidemic listeriosis is caused by type $4 \mathrm{~b}$.

\section{ACKNOWLEDGMENTS}

To Carla Oliveira Rosas and Márcia Barbosa Warnken (Food Lab., Microbiology Departament, INCQS-Fiocruz), to Catia A. Chaia Miranda Fernandes, Maysa Beatriz Mandetta Clementino, Letícia Schroeder and Nathalia Caldeira (Microbiology Department, INCQS-Fiocruz) and Deyse Christina Vallim da Silva (Bacterial Zoonosis Lab. IOC-Fiocruz).

\section{REFERENCES}

Bubert A, Hein I, Raunch M, Lehner A, Yoon B, Goebel W, Wagner M 1999. Detection and differentiation of Listeria spp. by a single reaction based on Multiplex PCR. Appl Environ Microbiol 65: 4688-4692.

Chen Y, Knabel S 2007. Multiplex PCR for simultaneous detection of bacteria of the genus Listeria, Listeria monocytogenes and major serotypes and epidemic clones of L. monocytogenes. Appl Environ Microbiol 73: 6299-6304.

Doumith M, Buchrieser C, Glaser P, Jaquet C, Martin P 2004a. Differentiation of the major Listeria monocytogenes serovars by Multiplex PCR. J Clin Microbiol 42: 3819-3822.

Doumith M, Cazalet C, Simoes N, Frangeul L, Jacquet C, Kunst F, Martin P, Cossart P, Glaser P, Buchrieser C 2004b. New aspects regarding evolution and virulence of Listeria monocytogenes revealed by comparative genomics and DNA arrays. Infec Immun 72: $1072-1083$.

Doumith M, Jacquet C, Gerner-Smidt P, Graves LM, Loncaveric S, Mathisen T, Morvan A, Salcedo C, Torpdahl M, Vasquez JA, Martin P 2005. Multicenter validation of a Multiplex PCR assay for differentiating the major Liste-ria monocytogenes serovars 1/2a, 1/2b, 1/2c and 4b: toward an international standard. $J$ Food Prot 68: 2648-2650.

Ericsson H, Stålhandske P, Danielsson-Tham ML, Bannerman E, Bille J, Jacquet C, Rocourt J, Tham W 1995. Division of Listeria monocytogenes serovar $4 \mathrm{~b}$ strains into two groups by PCR and restriction enzyme analysis. Appl Environ Microbiol 61: 3872-3874.

Gandhi M, Chikindas ML 2007. Listeria: a foodborne pathogen that knows how to survive. Int J Food Microbiol 113: 1-15.

Gasanov U, Hughes D, Hansbro PM 2005. Methods for isolation and identification of Listeria spp. and Listeria monocytogenes: a review. FEMS Microbiol Rev 29: 851-875.
Gray M, Zadoks RN, Fortes ED, Dogan B, Cai S, Chen Y, Scott VN, Gombas PE, Boor KJ 2004. Listeria monocytogenes isolates from foods and humans form distinct but overlapping populations. Appl Environ Microbiol 70: 5833-5841.

Hofer E, Hofer CB 2005. Listeriose. In J Rodrigues Coura (ed), Dinâmica das doenças infecciosas e parasitárias. Guanabara Koogan, Rio de Janeiro, p. 1539-1546.

Hofer E, Reis CMF, Hofer CB 2006. Serovars of Listeria monocytogenes and related species isolated from human clinical specimens. Rev Soc Bras Med Trop 39: 32-37.

Jacquet C, Doumith M, Gordon JI, Matin PMV, Cossat P, Lecerit M 2004. A molecular marker for evaluating the pathogenic potential of foodborne Listeria monocytogenes. J Infect Dis 189: 2094-2100.

Kathariou S 2002. Listeria monocytogenes virulence and pathogenicity, a food safety perspective. J Food Prot 65: 1811-1829.

Kaur S, Malik SV, Vaidya VM, Barbuddhe SB 2007. Listeria monocytogenes in spontaneous abortions in humans and its detection by Multiplex PCR. J Appl Microbiol 103: 1889-1896.

Liu D, Lawrence ML, Austin FW, Ainsworth AJ 2007. A Multiplex PCR for species and virulence-specific determination of Listeria monocytogenes. J Microbiol Methods 71: 133-140.

Nelson K, Fouts DE, Mongodin EF, Ravel J, DeBoy RT, Kolonay JF, Rasko D, Angiuoli SV, Gill SR, Paulsen IT, Peterson J, White O, Nelson WC, Nierman W, Beanan MJ, Brinkac LM, Daugherty SC, Dodson RJ, Durkin AS, Madupu R, Haft DH, Selengut J, Van Aken S, Khouri H, Fedorova N, Forberger H, Tran B, Kathariou S, Wonderling LD, Uhlinch GA, Bayles DO, Luchanshy JB, Fraser CM 2004. Whole genome comparisons of serovar $4 \mathrm{~b}$ and 1/2a strains of the food borne pathogen Listeria monocytogenes reveal new insights into the core genome components of this species. Nucleic Acids Res 32: 2386-2395.

Ramaswamy V, Cresence VM, Rejitha JS, Lekshmi MU, Dharsana KS, Prasad SP, Vijila HM 2007. Listeria: review of epidemiology and pathogenesis. J Microbiol Immunol Infec 40: 4-13.

Rocourt J, Schrettenbrunner A, Seeliger HPR 1983. Differentiation biochinique des groupes génomiques de Listeria monocytogenes (sensu lato). Ann Microbiol (Inst Pasteur) 134A: 65-71.

Scotter SL, Langton S, Lombard B, Schulten S, Nagelkerke N, In ${ }^{\circ} t$ Veld PH, Rollier P, Lahellec C 2001. Validation of ISO method 11290 Part 1 - Detection of Listeria monocytogenes in foods. Int J Food Microbiol 64: 295-306.

Seeliger HPR, Höhne K 1979. Listeria monocytogenes and related species. In T Bergan \& JR Norris (eds), Methods in Microbiology, Academic Press, London, p. 31-49. 